\title{
Modeling and Optimization of Electric Discharge Machining Performances using Harmony Search Algorithm
}

\author{
Ashanira Mat Deris ${ }^{1 *}$, AzlanMohd Zain ${ }^{1}$, Roselina Sallehuddin $^{1}$ and Safian Sharif ${ }^{2}$ \\ ${ }^{1}$ School of Computing, Faculty of Engineering, Universiti Teknologi Malaysia, 81310 UTM Skudai, Johor, Malaysia. \\ ${ }^{2}$ School of Mechanical Engineering, Faculty of Engineering, Universiti Teknologi Malaysia, 81310 UTM Skudai, Johor, \\ Malaysia.
}

"Corresponding author: ashanira.md@gmail.com.

\begin{abstract}
Electric Discharge Machining (EDM) is one of the widely used non-conventional machining processes for complex and difficult-to-machine materials. EDM technology has been improve significantly and has been developed in many ideas especially in the manufacturing industries that yielded enormous benefits in economic as well as generating keen interest in research area. A major issue in EDM process is how to obtain accurate results of the machining performance measurement value at optimal point of cutting conditions. Thus, this study proposed harmony search algorithm approach for optimization of surface roughness ( $\mathrm{Ra}$ ) in die sinking electric discharge machining (EDM). The mathematical model was developed using regression analysis based on four machining parameters which are pulse on time, peak current, servo voltage and servo speed. The result shows that the optimal solutions for Ra can be found with the minimum values of 1.3031 $\mu \mathrm{m}$.
\end{abstract}

Keywords:Harmony Search, Regression, Electric Discharge Machining, Surface Roughness, Electrode Wear Rate

Article History: received 4 September 2019; accepted 1 December 2019; published 24 December 2019.

(C) 2019 Penerbit UTM Press. All rights reserved

\section{INTRODUCTION}

Machining can be defined as a material removing process from the work piece in a form of chips. There are three major components in machining process which are work piece, cutting tool and machine tool. Machining process can be divided into two types namely conventional and non-conventional machining. Conventional machining consists of traditional way of work piece removal process such as turning, milling, grinding and boring while nonconventional machining consist of chemical items or advanced technologies used for the cutting process such as electric discharge machining (EDM), electrochemical machining (ECM), abrasive water jet (AWJ) and laser beam machining (LBM) [1]. This study only focuses on EDM process which is well known as a successfully applied machining process for the geometrically complex parts, hard and difficult-to-machine materials [2]. EDM technology is a reliable, affordable and accurate process which is commonly used in automobile, surgical industries, molds, and aerospace fields.

EDM has unique feature that differs from other machining process. The direct contact does not occurred in EDM during the cutting process between the work piece and electrode when eliminating mechanical stresses, chatter and vibration problems. EDM technology has been improve significantly and has been developed in many ideas especially in the manufacturing industries that yielded enormous benefits in economic as well as generating keen interest in research area. There are different types of EDM that have been interest by researchers including die-sinking EDM, wire EDM (WEDM), powder-mixed EDM, Dry EDM and MicroEDM [3].

EDM process was widely studied by previous researcher including modeling and optimization of machining performances using different approaches. Dewangan et al. [4] investigate the optimal solution of Ra in EDM process based on hybrid grey-fuzzy optimization approach on AISI P20 tool steel. The experiment was conducted using response surface methodology with pulse on time, tool lift time and tool work time as process parameters. The optimal solution was found and the result indicates that pulse on time is the most significant parameters affecting Ra value. Garg et al. [5] applied grey relational analysis (GRA) to find the optimal solution of $\mathrm{Ra}$ in EDM process using aluminum metal matrix composite. The experiment was conducted with pulse on time, pulse off time, peak current and gap voltage as input parameters. The optimal solution of Ra was found with pulse on time contributed more significantly to Ra. A new trend of optimization process using artificial intelligent approach has been evolves significantly over the years [6]. Meta-heuristic approaches such as simulated annealing (SA), ant colony optimization (ACO), bat algorithm (BA), firefly algorithm (FA), cuckoo search algorithm (CS) and harmony search (HS) optimization among the interest of 
many researchers [7-9]. These optimization approaches are proven to give better results compared with conventional optimization approaches.

Raja et al. [10] optimized the EDM parameters on hardened die steel using FA and it was found that FA is suitable for solving machining parameters optimization problem as the proposed model reduces time and cost of machining trials for surface roughness prediction. Teimouri and Baseri[11] optimized EDM parameters to determine the optimal solution of MRR and Ra based on ACO approach. The experiment was conducted with SPK (X210Cr12) cold work steel work piece with $99.9 \%$ copper electrode. The result found that continuous ACO has successfully determined the optimal solution of EDM performances. Rao and Venkaiah [12] optimized WEDM parameters of niminic-263 alloy using PSO algorithm. The mathematical model for material removal rate (MRR) and surface roughness $(\mathrm{Ra})$ were developed based on RSM. The result shows that PSO gave better performance compared with RSM. Based on the review, the optimization of EDM parameters based on Harmony Search approach is still lacking, hence this paper proposed HS approach in order to find the optimal solution of Ra performance in EDM process.

\section{METHODOLOGY}

The experiment is conducted using AG40L die sinking EDM with stainless steel $316 \mathrm{~L}$ as a work piece and copper impregnated graphite electrode. The work piece and electrode are shown in Figure 1 and Figure 2 respectively. The details chemical composition and mechanical properties of SS 316L are shown in Table 1 and Table 2 respectively.

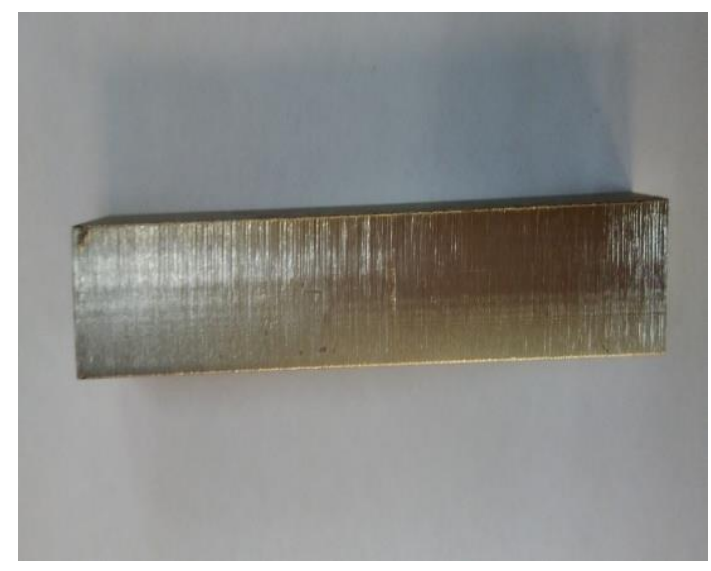

Figure 1. Stainless steel SS316L work piece

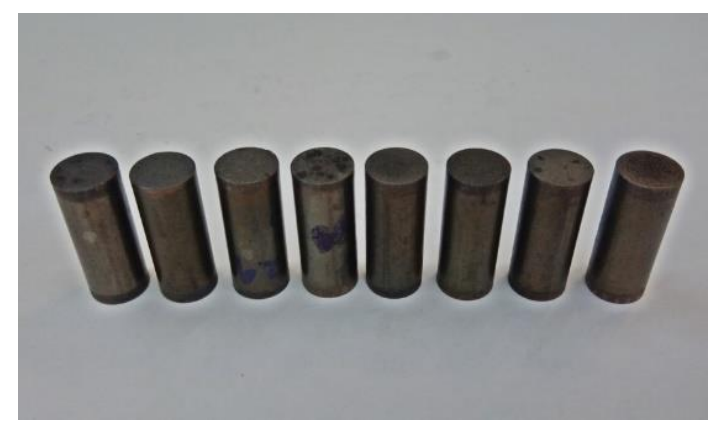

Figure 2. Copper impregnated graphite electrode
Table 1. Chemical composition of SS 316L

\begin{tabular}{|c|c|}
\hline Elements & 316L (wt \%) \\
\hline $\mathrm{C}$ & 0.026 \\
\hline $\mathrm{Si}$ & 0.37 \\
\hline $\mathrm{Mn}$ & 0.16 \\
\hline $\mathrm{Cr}$ & 16.55 \\
\hline $\mathrm{Cu}$ & 0.16 \\
\hline $\mathrm{Ni}$ & 10.0 \\
\hline $\mathrm{P}$ & 0.029 \\
\hline $\mathrm{S}$ & 0.027 \\
\hline $\mathrm{Mo}$ & 2.02 \\
\hline $\mathrm{N}$ & 0.036 \\
\hline $\mathrm{Fe}$ & Balance \\
\hline
\end{tabular}

Table 2. Mechanical properties of SS 316L

\begin{tabular}{|c|c|c|}
\hline Mechanical Properties & Typical & Minimum \\
\hline Tensile Strength & $600 \mathrm{Mpa}$ & $485 \mathrm{Mpa}$ \\
\hline Proof Strength, (offset 0.2\%) & $310 \mathrm{Mpa}$ & $170 \mathrm{Mpa}$ \\
\hline Elongation (Percent in 50mm) & 60 & 40 \\
\hline Hardness (Brinell) & 217 & - \\
\hline Hardness (Rockwell) & 95 & - \\
\hline Endurance (Fatigue Limit) & $240 \mathrm{Mpa}$ & - \\
\hline
\end{tabular}

DOE is the design setting that needs to be completed prior to the experimental process can be run. In this study, the experiment is conducted based on two levels full factorial design which involves four parameters as input variables. Before conducting the experiment, the ranges for low (-) and high (+) levels for each parameter are determined based on EDM manual handbook or previous studies. Table 3 shows the range value for EDM parameters.

Table 3. The range value of EDM parameters

\begin{tabular}{|l|c|c|c|}
\hline \multirow{2}{*}{ Machining Parameters } & \multirow{2}{*}{ Unit } & \multicolumn{2}{|c|}{ Levels } \\
\cline { 3 - 4 } & & $\mathbf{1}$ & $\mathbf{2}$ \\
\hline Pulse on time (ToN) & $\mu \mathrm{s}$ & 100 & 200 \\
\hline Peak Current (Ip) & $\mathrm{A}$ & 5.7 & 10.5 \\
\hline Servo Voltage (Vs) & $\mathrm{V}$ & 30 & 90 \\
\hline Servo Speed (S) & $\mathrm{s}$ & 74 & 92 \\
\hline
\end{tabular}

Based on the Table 3, it can be seen that there are four machining parameters considered in this study which are pulse on time $\left(\mathrm{T}_{\mathrm{ON}}\right)$, Peak Current (Ip), Servo Voltage (Vs) and Servo Speed (S). The range value for $\mathrm{T}_{\mathrm{ON}}$ is $[100,200]$, range value for Ip is [5.7, 10.5], range value for Vs is [30, 90] and the range value for $S$ is [74, 92]. After conducting the machining experiment, the machining data for $\mathrm{Ra}$ was collected and analyzed. The value of surface roughness value was measured using surface roughness tester. Table 4 shows the experimental result of $\mathrm{Ra}$.

\subsection{Modeling}

The data collected was used to develop a mathematical model based on regression approach. It acts as an objective function for optimization process. To validate 
the model developed, analysis of variance (ANOVA) is used.

Table 4. Ra experimental result

\begin{tabular}{|c|c|c|c|c|c|}
\hline \multirow[b]{2}{*}{ No } & \multicolumn{4}{|c|}{ Parameters } & \multirow[b]{2}{*}{$\mathbf{R a}(\boldsymbol{\mu m})$} \\
\hline & $\begin{array}{r}\text { Ton } \\
(\mu s)\end{array}$ & $\begin{array}{c}\text { Ip } \\
(\mathbf{A})\end{array}$ & $\begin{array}{c}\mathbf{V s} \\
(\mathrm{V})\end{array}$ & $\begin{array}{c}\mathbf{S} \\
(\mathbf{s})\end{array}$ & \\
\hline 1 & 100.00 & 5.70 & 30.00 & 74.00 & 1.8791 \\
\hline 2 & 100.00 & 10.50 & 30.00 & 74.00 & 2.3766 \\
\hline 3 & 100.00 & 5.70 & 90.00 & 74.00 & 1.5366 \\
\hline 4 & 100.00 & 10.50 & 90.00 & 74.00 & 4.0896 \\
\hline 5 & 100.00 & 5.70 & 30.00 & 92.00 & 1.6486 \\
\hline 6 & 100.00 & 10.50 & 30.00 & 92.00 & 5.5439 \\
\hline 7 & 100.00 & 5.70 & 90.00 & 92.00 & 1.7243 \\
\hline 8 & 100.00 & 10.50 & 90.00 & 92.00 & 2.9212 \\
\hline 9 & 200.00 & 5.70 & 30.00 & 74.00 & 1.6429 \\
\hline 10 & 200.00 & 10.50 & 30.00 & 74.00 & 2.7060 \\
\hline 11 & 200.00 & 5.70 & 90.00 & 74.00 & 1.7071 \\
\hline 12 & 200.00 & 10.50 & 90.00 & 74.00 & 2.5712 \\
\hline 13 & 200.00 & 5.70 & 30.00 & 92.00 & 3.4499 \\
\hline 14 & 200.00 & 10.50 & 30.00 & 92.00 & 4.1105 \\
\hline 15 & 200.00 & 5.70 & 90.00 & 92.00 & 1.4481 \\
\hline 16 & 200.00 & 10.50 & 90.00 & 92.00 & 2.4101 \\
\hline
\end{tabular}

ANOVA is a statistical approach of portioning variability into identifiable sources of variation and the associated degree of freedom in an experiment. In modeling of $\mathrm{Ra}$, it is generally expressed mathematically in terms of arithmetic average deviation from the mean. The mathematical model equation for $\mathrm{Ra}$ modeling is specified in Equation 1 [6].

$$
R_{a}=\frac{1}{L} \int_{0}^{L}|Y(x)| d x
$$

where $L$ is the sampling length and $Y$ is the ordinate of the profile curve. The minimization of the $\mathrm{Ra}$ must be formulated in the standard mathematical model which can be expressed as in in Equation 2.

$$
R_{a}=k \prod_{i=1}^{n} c_{i}^{e_{i}}
$$

The final $\mathrm{Ra}$ mathematical model is written as in Equation 3 [13].

$$
R_{a}=k c_{1}^{e_{1}} c_{2}^{e_{2}} c_{3}^{e_{3}} \ldots c_{n}{ }^{e_{n}}
$$

Where $R_{a}$ is the predicted surface roughness (respond variable), $c_{1} \ldots c_{n}$ is the EDM parameters, and $k, e_{1}, e_{2} \ldots . e_{n}$ are the model parameters to be predicted using the experimental data. To develop the regression model for $\mathrm{Ra}$, the model given in Equation 3 is linearized by performing a logarithmic transformation. Multi linear regression model of $\mathrm{Ra}$ can be expressed as in Equation 4:

$$
\begin{aligned}
& \operatorname{MLR}(\mathrm{Ra})=-1.65988-2.09263 E 003 * T_{O N}+0.30449 * I p- \\
& 0.010311 * V s+0.032769 * S
\end{aligned}
$$

Where $\mathrm{Ra}$ is surface roughness in $\mu \mathrm{s}, \mathrm{T}_{\mathrm{ON}}$ is pulse on time in $\mu \mathrm{s}$, Ip is peak current in $\mathrm{A}, \mathrm{Vs}$ is servo voltage in $\mathrm{V}$ and $\mathrm{S}$ is servo speed. The Ra model then analyzed using
ANOVA analysis. Table 5 shows the ANOVA result of MLR for Ra.

Table 5. ANOVA of MLR for Ra

\begin{tabular}{|c|c|c|c|c|c|}
\hline $\begin{array}{c}\text { EDM } \\
\text { parameters }\end{array}$ & $\begin{array}{c}\text { Sum } \\
\text { Square }\end{array}$ & DF & $\begin{array}{c}\text { Mean } \\
\text { Square }\end{array}$ & $\begin{array}{c}\text { F } \\
\text { Value }\end{array}$ & P-value \\
\hline Model & 11.66 & 4 & 2.91 & 3.65 & 0.0398 \\
\hline TON & 0.18 & 1 & 0.18 & 0.22 & 0.6488 \\
\hline Ip & 8.54 & 1 & 8.54 & 10.69 & 0.0075 \\
\hline Vs & 1.53 & 1 & 1.53 & 1.92 & 0.1938 \\
\hline S & 1.41 & 1 & 1.41 & 1.76 & 0.2112 \\
\hline Residual & 8.79 & 11 & 0.80 & & \\
\hline
\end{tabular}

From Table 5, the result of the ANOVA indicates that the MLR model for $\mathrm{Ra}$ is statistically significant with the $\mathrm{P}$-value of 0.0398. P-value that is equal or less than 0.05 is considered as significant, while P-value that is higher than 0.05 is considered as insignificant. For each machining parameter in MLR model, the result shows that only peak current is the significant to the model with the P-value $=0.0075$, while other machining parameters are insignificant to the model with the $\mathrm{P}$-values are greater than 0.05 . The value of R-Squared for the model is 0.5701 , which is the model considered as a reasonable to be accepted.

\subsection{HS Optimization}

Harmony Search is a new meta-heuristic algorithm that mimicking the improvisation of music players to search for a perfect state of melody or harmony [14]. The optimization process is applied when musician plays different music notes on different instrument to find the best combination of frequency for a best tune. The steps for HS optimization as follows:

Step 1: Initialization of HS parameters.

i. Harmony memory size (HMS) defines the number of solution vectors in HM.

ii. Harmony memory considering rate (HMCR), $\mathrm{HMCR} \in[0,1]$ which determine the selection rate from the memory.

iii. Pitch Adjusting Rate (PAR) $\in[0,1]$ which determines the probability of local improvement.

iv. The fret width (FW) which determines the adjustment of the distance.

v. Number of iterations (NI) or number of improvisations.

Step 2: Initialization of harmony memory (HM).

$\mathrm{HM}$ is a storage area for the population individuals, which is called as solution vector where $\mathrm{HM}=\left[x^{l}, \ldots . x^{\mathrm{HMS}}\right]^{\mathrm{T}}$ of the size HMS. In this step, these solution vector are generated randomly as $x_{i}^{j}=L B_{i}+\left(U B_{i}-L B_{i}\right) \times U(0,1), \forall=$ $1,2, \ldots, N$ and $\forall j=1,2, . . H M S$, and $\mathrm{U}(0,1)$ generates a uniform random number between 0 and 1 .

Step 3: Improvisation of a new harmony.

Harmony vector is improvised to generate a new harmony vector $x^{\prime}=\left(x_{i}^{\prime}, x_{2}^{\prime}, \ldots, x_{N}^{\prime}\right)$, based on 
three rules: (i) memory consideration (MC), (ii) pitch adjustment (PA), and (iii) random selection (RS). The three rules assign a value for each decision variable $x_{i}^{\prime}$ in the new harmony as formulated in Equation 5 as follows:

$$
x_{i}^{l} \leftarrow\left\{\begin{array}{c}
x_{i}^{\prime} \in\left\{x_{i}^{1}, x_{i}^{2}, \ldots x_{i}^{H M S} \text { w. p HMCR } \mathrm{x}(1-P A R)\{M C\}\right. \\
x_{i}^{\prime}=x_{i}^{\prime}+U(-1,1) x F W \quad \text { w. } \mathrm{HMCR} \mathrm{x} P A R \quad\{P A\} \\
x_{i}^{\prime} \in X_{i} \text { w.p }(1-H M C R) \quad\{R C\}
\end{array}\right.
$$

Step 4: Update the HM

The worst harmony is replaced by a new harmony vector, $x^{\prime}=\left(x_{i}^{\prime}, x_{2}^{\prime}, \ldots, x_{N}^{\prime}\right)$, that is stored in HM.

Step 5: Check the stop criterion

Repeat step 3 and step 4 until the stopping requirement (which is normally depends on NI) is met.

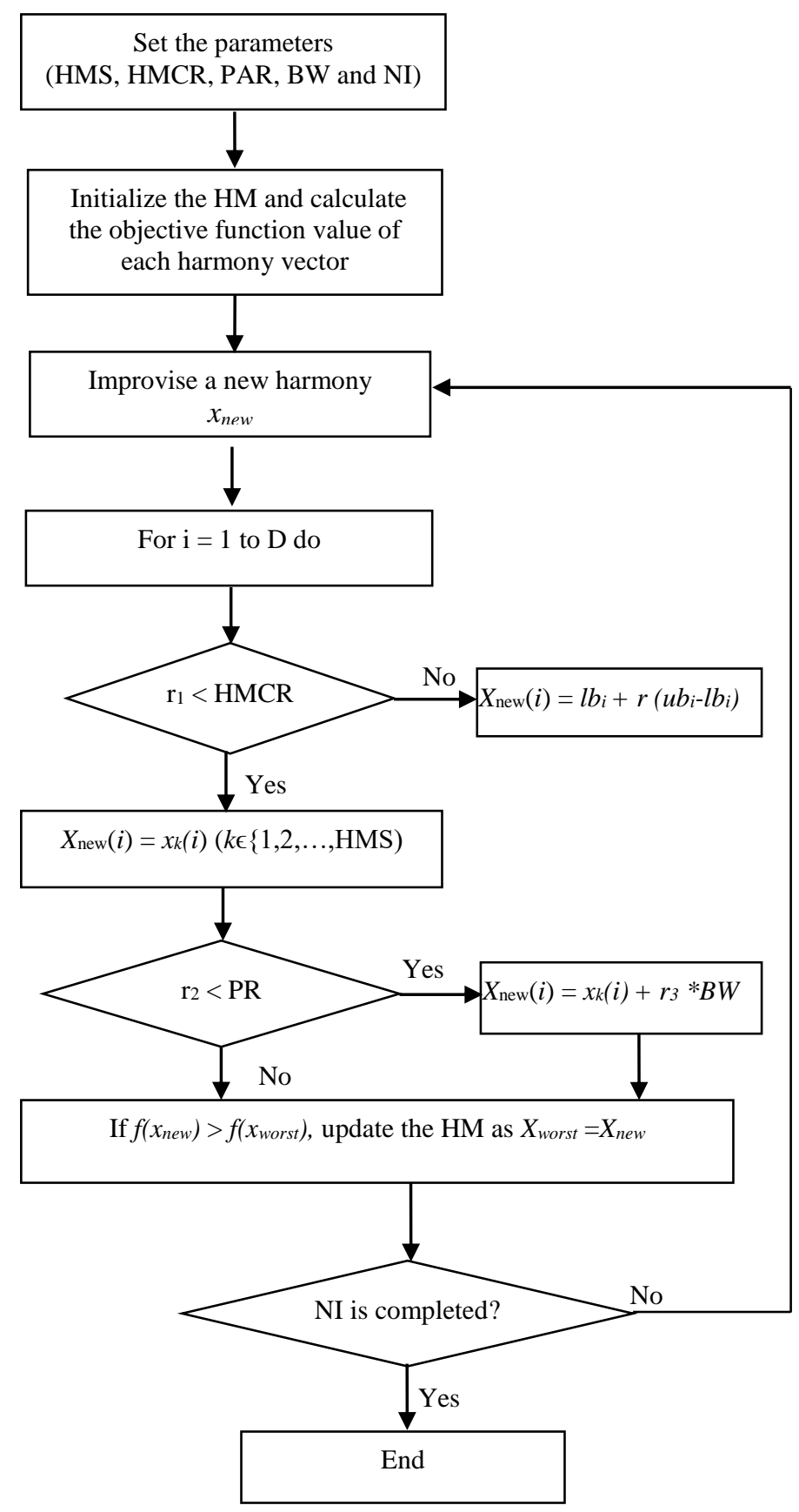

Figure 3. HS flowchart 


\section{RESULT ANALYSIS}

The aim of optimization process for $\mathrm{Ra}$ is to find the optimal value for each machining parameters that lead to the minimum value of Ra. Table 6 shows the optimization result of $\mathrm{Ra}$.

Table 6. HS optimal solution for Ra

\begin{tabular}{|c|c|c|c|}
\hline Models & $\begin{array}{c}\text { Optimal parameters } \\
\text { Ton, Ip, Vs, S } \\
(\boldsymbol{\mu s}, \mathbf{A}, \mathbf{V}, \mathbf{S})\end{array}$ & $\begin{array}{c}\text { Minimum } \\
\text { Ra }(\boldsymbol{\mu m})\end{array}$ & $\begin{array}{c}\text { Error } \\
(\boldsymbol{\%})\end{array}$ \\
\hline EXP & $200,5.7,90,92$ & 1.4481 & - \\
\hline MLR & $\begin{array}{c}197.6991,5.8559, \\
83.1139,74.7832\end{array}$ & 1.3031 & 10.01 \\
\hline
\end{tabular}

From Table 6, it can be seen that minimum Ra $=1.3031 \mu \mathrm{m}$ for MLR was given by the combination of optimal cutting solution of machining parameters $\mathrm{T}_{\mathrm{ON}}=$ $197.6991 \mu \mathrm{s}, \mathrm{I}_{\mathrm{p}}=5.8559 \mathrm{~A}, \mathrm{Vs}=83.1139 \mathrm{~V}$ and $\mathrm{S}=$ 74.7832 with the computing time $0.473 \mathrm{~s}$. For 2FI, minimum $\mathrm{Ra}=1.3346 \mu \mathrm{m}$ was given by $\mathrm{T}_{\mathrm{ON}}=100.0429$ $\mu \mathrm{s}, \mathrm{I}_{\mathrm{p}}=5.7 \mathrm{~A}, \mathrm{Vs}=36.0441 \mathrm{~V}$ and $\mathrm{S}=75.0415$ with the computing time $0.456 \mathrm{~s}$. For $\mathrm{SR}$, the minimum $\mathrm{Ra}=$ $1.8796 \mu \mathrm{m}$ was given by $\mathrm{T}_{\mathrm{ON}}=129.0690 \mu \mathrm{s}, \mathrm{I}_{\mathrm{p}}=5.7 \mathrm{~A}$, $\mathrm{Vs}=77.9637 \mathrm{~V}$ and $\mathrm{S}=89.7334$ with the computing time 0.420 , while for $\mathrm{PR}$ model, minimum $\mathrm{Ra}=1.2444 \mu \mathrm{m}$ was given by $\mathrm{T}_{\mathrm{ON}}=193.0109 \mu \mathrm{s}, \mathrm{I}_{\mathrm{p}}=5.7 \mathrm{~A}, \mathrm{Vs}=87.3162$ $\mathrm{V}$ and $\mathrm{S}=74.5226$ with the computing time $0.364 \mathrm{~s}$, The percentage error of $2 \mathrm{FI}$ model is the lowest compared to other models, which is $7.84 \%$. The results of HS optimization for Ra was validate with the substitution of the optimal combination of machining parameters to the mathematical equation in order to compare the values of machining performances, as in Equation 5. The result can be taken as the indicators that the same results will obtained when this optimal solution are tested through the actual experiment process.

$$
\begin{array}{r}
\mathrm{Ra}=-1.65988-2.09263 \mathrm{E} 003(197.6991)+ \\
0.30449(5.8559)-0.010311(83.1139)+ \\
0.032769(74.7832)=1.3031 \mu \mathrm{m}
\end{array}
$$

\section{CONCLUSION}

Experiment data shows lowest Ra which is $1.4481 \mu \mathrm{m}$, was obtained at the combination of high pulse on time, low peak current, high servo voltage and high servo speed. Low energy discharges to the work piece material causing the better surface finish which resulted in lower $\mathrm{Ra}$ value. Increasing value of peak current generates the higher energy that leads to the strong spark during the machining process. Thus, the rougher surface finished is obtained.

Choosing the right approach to develop mathematical model is crucial task as it will affect the optimization result. The developed models were used as objective function in optimization process. The regression model developed for $\mathrm{Ra}$ was found significant by giving the $\mathrm{p}$ value less than 0.05 .

HS has been proven to give better result in solving optimum solution of optimization problem. With the few parameters involved, HS has been widely considered by previous researchers in various fields including machining and manufacturing. In this study, HS optimization give better result compared with experimental by giving the minimum value of $\mathrm{Ra}, 1.3031$ $\mu \mathrm{m}$ with the $10.01 \%$ improvement.

\section{ACKNOWLEDGMENT}

Special appreciative to reviewer(s) for the useful advices and comments. The authors greatly acknowledge the Research Management Centre, UTM for financial support through the Research University Grant (GUP) Vot. No. Q.J130000.2528.14H

\section{REFERENCES}

[1] Deris, A. M., Zain, A. M., \&Sallehuddin, R. (2013). Hybrid GR-SVM for prediction of surface roughness in abrasive water jet machining. Meccanica, 48(8), 1937-1945.

[2] Cole, J., Alzofiri, S., Gallardo, V., Pasillas, M., and James, S. (2017). Design and Fabrication of a Micro Electro Discharge Machining System.

[3] Holmberg, J., Wretland, A., \& Berglund, J. (2016). Grit blasting for removal of recast layer from EDM process on Inconel 718 Shaft: an evaluation of surface integrity. Journal of Materials Engineering and Performance, 25(12), 5540-5550.

[4] Dewangan, S., Gangopadhyay, S., \& Biswas, C. K. (2015). Multi-response optimization of surface integrity characteristics of EDM process using greyfuzzy logic-based hybrid approach. Engineering Science and Technology, an International Journal, 18(3), 361-368.

[5] Garg, H. K., Kumar, R., \& Manna, A. (2017). Multi Response Optimization of Electric Discharge Machining (EDM) Parameters for Machining Hybrid Aluminum Metal Matrix Composite using Grey Relation Analysis (GRA).

[6] Zain AM, Haron H, Sharif S. Estimation of the minimum machining performance in the abrasive waterjet machining using integrated ANN-SA. Expert SystAppl 2011; 38 (7):8316-26.

[7] Mohamad, A., Zain, A. M., Bazin, N. E. N., \&Udin, A. (2015). A process prediction model based on Cuckoo algorithm for abrasive waterjet machining. Journal of Intelligent Manufacturing, 26(6), 1247-1252.

[8] Zainal, N., Zain, A. M., Radzi, N. H. M., \& Othman, M. R. (2016). Glowworm swarm optimization (GSO) for optimization of machining parameters. Journal of Intelligent Manufacturing, 27(4), 797-804.

[9] Kamaruzaman, A. F., Zain, A. M., Yusuf, S. M., \&Udin, A. (2013). Levy flight algorithm for optimization problems-a literature review. In Applied Mechanics and Materials (Vol. 421, pp. 496-501). Trans Tech Publications.

[10] Raja, S. B., Pramod, C. S., Krishna, K. V., Ragunathan, A., \&Vinesh, S. (2015). Optimization of electrical discharge machining parameters on hardened die steel using Firefly Algorithm. Engineering with Computers, 31(1), 1-9.

[11] Teimouri, R., \&Baseri, H. (2014). Optimization of magnetic field assisted EDM using the continuous 
ACO algorithm. Applied Soft Computing, 14, 381389.

[12] Rao, M. S., \&Venkaiah, N. (2015). Parametric optimization in machining of Nimonic-263 alloy using RSM and particle swarm optimization. Procedia Materials Science, 10, 7079.
[13] Caydas, U., \& Hascalik, A. (2008). A study on surface roughness in abrasive waterjet machining process using artificial neural networks and regression analysis method. Journal of Materials Processing Technology, 202, 574-582.

[14] Geem,Z. W., Kim, J. H., \&Loganathan, G. V. (2001). A New Heuristic Optimization Algorithm: Harmony Search. Simulation, 76(2), 60-68. 